\title{
Erratum to: The "Persuadable Middle" on Same-Sex Marriage: Formative Research to Build Support among Heterosexual College Students
}

Michael R. Woodford • Jill Chonody • Kristin Scherrer • Perry Silverschanz • Alex Kulick

Published online: 30 June 2012

(C) Springer Science+Business Media, LLC 2012

Erratum to: Sex Res Soc Policy DOI 10.1007/s13178-011-0073-y

Published in Volume 9, Number 1, pp. 1-14

In the right-hand column of Table 2 (page 7), the following three test statistics were inadvertently set in italic; they should be bold as indicated below:

Political ideology ${ }^{\mathrm{c}}$

$0.75(0.61,0.92)$

Malleability of same-sex sexuality ${ }^{\mathrm{d}}$

$1.20(1.03,1.41)$

Acceptability of same-sex relationships $^{\mathrm{d}} \quad \mathbf{0 . 7 0}(\mathbf{0 . 6 1}, \mathbf{0 . 7 9})$

The online version of the original article can be found at http://dx.doi.org/ 10.1007/s13178-011-0073-y.

M. R. Woodford ( $\square$ )

School of Social Work, University of Michigan,

1080 S. University Avenue, Ann Arbor, MI 48109-1106, USA

e-mail: michwood@umich.edu

J. Chonody

School of Psychology, Social Work and Social Policy,

University of South Australia,

St. Bernards Rd., Magill, South Australia 5072, Australia

K. Scherrer

School of Social Work, Rutgers,

The State University of New Jersey,

536 George St., New Brunswick, NJ 08901, USA

P. Silverschanz

School of Social Work \& Department of Psychology,

University of Michigan,

1080 S. University Avenue, Ann Arbor, MI 48109-1106, USA

\section{A. Kulick}

Women's Studies, University of Michigan,

1080 S. University Avenue, Ann Arbor, MI 48109-1106, USA 